\title{
Ehlers-Danlos Syndrome, Type V
}

National Cancer Institute

\section{Source}

National Cancer Institute. Ehlers-Danlos Syndrome, Type V. NCI Thesaurus. Code C141423.

An X-linked condition characterized by joint hyperextensibility, mild skin hyperelastisity, and abnormal scarring. The molecular basis for this condition has not been fully elucidated. 